\title{
Filling the gaps: need for research on cell-specific xenobiotic metabolism in the skin
}

\author{
Charlotte Esser • Christine Götz
}

Received: 5 February 2013/Accepted: 25 February 2013/Published online: 8 March 2013

(C) Springer-Verlag Berlin Heidelberg 2013

The removal and metabolism of organic molecules is a pivotal body function, usually performed by phase I and phase II enzymes. While detoxification is beneficial and necessary, at the same time, the metabolic intermediates and breakdown products generated in the process can have immunogenic, cancerogenic or apoptogenic potential, which differs from the respective parental chemical. Whether and which adverse health effects ensue depends on the affected cell types and tissue. For instance, if damage caused by a chemical induces apoptosis, easily regenerating tissues may cope better than slowly proliferating or rare precursor cells. On the other hand, potential extent of damage is conceivably dependent on the xenobiotic metabolizing activity of cell types, which in turn might be governed by exposure, that is, tissues with high exposure could be more competent in xenobiotic metabolism. There is, however, a surprising lack of research to identify cell-specific xenobiotic metabolism. Research on the molecular activity of xenobiotic metabolizing enzymes (XME) has traditionally a strong focus on the liver as the main metabolizing and detoxifying organ of the body. The skin is less well studied, albeit it forms a major barrier against the environment (including the chemical environment) and is a target of occupational, accidental and intended-use (i.e., cosmetics and pharmaceuticals) chemical exposure. Risks of exposure are irritation, inflammation, allergies and cancer. Conceivably, skin cells may possess yet underestimated strategies to balance XMEmediated danger.

C. Esser $(\bowtie)$. C. Götz

Leibniz Research Institute for Environmental Medicine (IUF),

Auf'm Hennekamp 50, 40225 Düsseldorf, Germany

e-mail: charlotte.esser@uni-duesseldorf.de;

chesser@uni-duesseldorf.de
In a recent paper, the team around Michael Girardi (Modi et al. 2012) presented the exciting finding that differential expression of phase I enzymes CYP4501A1 and 1B1 in skin Langerhans cells versus keratinocytes leads to generation of DNA-modifying metabolites from the carcinogen 7,12-Dimethylbenz[a]anthracen (DMBA) in the skin and eventually non-melanoma skin cancer. They found that skin Langerhans cells efficiently metabolize DMBA to DMBA-3,4-diol which leads to oncogenic Hras mutations. Mice lacking skin Langerhans cells had fewer skin tumours upon DMBA treatment. They conclude "Thus, tissue-associated dendritic cells can enhance chemical carcinogenesis via PAH metabolism, highlighting the complex relation between immune cells and carcinogenesis." While the paper of Girardi and colleagues looks at chemical-induced (DMBA-induced) cancer, it has also important implications for understanding skin physiology and skin toxicology.

Sun light, that is, its UV radiation component, is the most important stressor of skin (Fritsche et al. 2007) and has long been known to be genotoxic and a major risk factor in skin cancer (Narayanan et al. 2010). UV and UVinduced DNA damage are the primary cause not only for melanoma with increasing incidence and new cases worldwide every year (Little and Eide 2012), but also of skin basal cell carcinoma, squamous cell carcinoma, Kaposi's sarcoma and others. Recent studies confirmed that UV radiation sensitizes keratinocytes to polycyclic aromatic hydrocarbons (PAH)-mediated DNA adduct formation (Nair et al. 2009), and therefore, the physiological interplay of UV radiation and chemical inducers should not be neglected. Both DMBA and UV are targeted toward the transcription factor AhR (aryl hydrocarbon receptor), which represents the chemical sensor in the skin and controls the transcription of genes for phase I and phase II 
enzymes. AhR can be activated both by DMBA and by amino-acid dimers generated by UV-light. AhR is highly expressed in all skin cell types, that is, in keratinocytes, Langerhans cells, dendritic epidermal $\mathrm{T}$ cells, melanocytes and fibroblasts, albeit differentially inducing XMEs. Intriguingly, some skin cells, but not all, appear to keep AhR activation in check by concomitantly expressing the AhR repressor (Jux et al. 2009; Tigges et al. 2012). Beyond orchestrating detoxification of chemicals, AhR plays an important role in skin cell homeostasis and the skin immune system (Esser 2012). This raises the question to what extent the expression levels of AhR and its activation by small chemical compounds is skin protective (by quickly removing dangerous chemicals) or genotoxic (by conversion of inert chemicals into toxic metabolites). The epidemiological connection between skin cancer and exposure to AhR-activating substances in workers (e.g., coal miners), or by lifestyle (in smokers!), or via UV radiation are well known. The results by Modi et al. are a dire warning to avoid this exposure.

Some important questions remain. Compared to liver, skin has historically been much less investigated or even considered as an actively metabolizing organ in toxicological studies. The situation is now changing. There is increasing interest to understand skin metabolism particularly in regard to chemical registration. The 7th amendment to the European Cosmetics Directive, for example, demands replacement methods for animal testing (Pauwels and Rogiers 2004). This requires, in consequence, better information on XME and their regulation for any proposed test model and for the target organ skin. Previous publications indicate that skin of various species is indeed well equipped with a broad range of xenobiotic metabolizing enzymes (for reviews see Gibbs et al. 2007; Oesch et al. 2007; Svensson 2009). Work from our own institute recently has proven that human whole skin as well as human keratinocytes, the main cell type of the epidermis, are equipped with both Phase I and II XME (Götz et al. 2012a, b). Interestingly, the CYP450 monooxygenase family 1 , which is an integral part of the publication of Modi et al., is neither expressed nor active in human keratinocytes without stimulus, but strongly reacts toward AhR ligands leading to physiologically relevant substrate turnover rates (Götz et al. 2012a) which have the potential to convert CYP1 from a protective to a detrimental XME activity. Almost nothing is known for XME profiles in human Langerhans cells compared to other skin dendritic cells and on the possibility of their differential expression levels upon chemical exposure or UV radiation (both could be mediated by AhR).

Apart from the above-discussed Langerhans cells, skin comprises a variety of specialized cells like keratinocytes, fibroblasts, stem cells, melanocytes, Merkel cells and others where there is still more need for information on xenobiotic metabolism and its regulation. Particularly, the latter two cell types are known to be involved in the development of aggressive skin tumors, melanoma (with UV radiation a major cause) and Merkel cell carcinoma (Andea et al. 2008), respectively. The involvement of metabolic processes in the formation of immuno-reactive compounds from xenobiotics, for example, via $\mathrm{N}$-acetylation (Aeby et al. 2009) or via functional loss of glutathione S-transferase activity (Lutz et al. 2001), is again of relevance in the context of the development of allergic reactions. Moreover, in human AhR polymorphisms exist some of which reduce AhR activity and conceivably XME balance, but whose relevance in skin cancer and skin health is entirely unexplored. Another important aspect is the likelihood of species specificity regarding xenobiotic metabolism (Gassmann et al. 2010). XME expression, specificity, tissue distribution and regulation or AhR activity might differ from human XME which must be considered in toxicological studies. Finally, the surprising finding of differential expression of XMEs between skin cells could be mirrored by differential expression of DNA repair enzymes (needed to repair damage from genotoxic chemicals). This is largely unexplored, albeit some evidence suggests that DNA repair enzymes are not uniformly expressed in all cells of the body (Bauer et al. 2011).

Taken together, there is a high demand to understand human skin xenobiotic metabolism on a cell- and speciesspecific level. Any such knowledge would also be welcome for preventive or therapeutic considerations, involving any disbalance of XME enzymes and eventually tipping the scale from protection to genotoxicity.

\section{References}

Aeby P, Sieber T, Beck H, Gerberick GF, Goebel C (2009) Skin sensitization to $p$-phenylenediamine: the diverging roles of oxidation and $N$-acetylation for dendritic cell activation and the immune response. J Invest Dermatol 129:99-109

Andea AA, Coit DG, Amin B, Busam KJ (2008) Merkel cell carcinoma: histologic features and prognosis. Cancer 113:25492558

Bauer M, Goldstein M, Christmann M, Becker H, Heylmann D, Kaina B (2011) Human monocytes are severely impaired in base and DNA double-strand break repair that renders them vulnerable to oxidative stress. Proc Natl Acad Sci USA 108:21105-21110

Esser C (2012) Biology and function of the aryl hydrocarbon receptor: report of an international and interdisciplinary conference. Arch Toxicol 86:1323-1329

Fritsche E, Schäfer C, Calles C, Bernsmann T, Bernshausen T, Wurm M, Hübenthal U, Cline JE, Hajimiragha H, Schroeder P, Klotz LO, Rannug A, Fürst P, Hanenberg H, Abel J, Krutmann J (2007) Lightening up the UV response by identification of the arylhydrocarbon receptor as a cytoplasmatic target for ultraviolet B radiation. Proc Natl Acad Sci USA 104:8851-8856 
Gassmann K, Abel J, Bothe H, Haarmann-Stemmann T, Merk HF, Quasthoff KN, Rockel TD, Schreiber T, Fritsche E (2010) Species-specific differential AhR expression protects human neural progenitor cells against developmental neurotoxicity of PAHs. Environ Health Perspect 118:1571-1577

Gibbs S, van de Sandt JJ, Merk HF, Lockley DJ, Pendlington RU, Pease CK (2007) Xenobiotic metabolism in human skin and 3D human skin reconstructs: a review. Curr Drug Metab 8:758-772

Götz C, Pfeiffer R, Tigges J, Blatz V, Jäckh C, Freytag EM, Fabian E, Landsiedel R, Merk HF, Krutmann J, Edwards RJ, Pease C, Goebel C, Hewitt N, Fritsche E (2012a) Xenobiotic metabolism capacities of human skin in comparison with a $3 \mathrm{D}$ epidermis model and keratinocyte-based cell culture as in vitro alternatives for chemical testing: activating enzymes (Phase I). Exp Dermatol 21:358-363

Götz C, Pfeiffer R, Tigges J, Ruwiedel K, Hübenthal U, Merk HF, Krutmann J, Edwards RJ, Abel J, Pease C, Goebel C, Hewitt N, Fritsche E (2012b) Xenobiotic metabolism capacities of human skin in comparison with a 3D-epidermis model and keratinocytebased cell culture as in vitro alternatives for chemical testing: phase II enzymes. Exp Dermatol 21:364-369

Jux B, Kadow S, Esser C (2009) Langerhans cell maturation and contact hypersensitivity are impaired in aryl hydrocarbon receptor-null mice. J Immunol 182:6709-6717

Little EG, Eide MJ (2012) Update on the current state of melanoma incidence. Dermatol Clin 30:355-361

Lutz W, Tarkowski M, Nowakowska E (2001) Genetic polymorphism of glutathione s-transferase as a factor predisposing to allergic dermatitis. Med Pr 52:45-51
Modi BG, Neustadter J, Binda E, Lewis J, Filler RB, Roberts SJ, Kwong BY, Reddy S, Overton JD, Galan A, Tigelaar R, Cai L, Fu P, Shlomchik M, Kaplan DH, Hayday A, Girardi M (2012) Langerhans cells facilitate epithelial DNA damage and squamous cell carcinoma. Science 335:104-108

Nair S, Kekatpure VD, Judson BL, Rifkind AB, Granstein RD, Boyle JO, Subbaramaiah K, Guttenplan JB, Dannenberg AJ (2009) UVR exposure sensitizes keratinocytes to DNA adduct formation. Cancer Prev Res (Phila) 2:895-902

Narayanan DL, Saladi RN, Fox JL (2010) Ultraviolet radiation and skin cancer. Int J Dermatol 49:978-986

Oesch F, Fabian E, Oesch-Bartlomowicz B, Werner C, Landsiedel R (2007) Drug-metabolizing enzymes in the skin of man, rat, and pig. Drug Metab Rev 39:659-698

Pauwels M, Rogiers V (2004) Safety evaluation of cosmetics in the EU: reality and challenges for the toxicologist. Toxicol Lett 151:7-17

Svensson CK (2009) Biotransformation of drugs in human skin. Drug Metab Dispos 37:247-253

Tigges J, Weighardt H, Wolff S, Gotz C, Forster I, Kohne Z, Huebenthal U, Merk HF, Abel J, Haarmann-Stemmann T, Krutmann J, Fritsche E (2012) Aryl Hydrocarbon Receptor Repressor (AhRR) Function revisited: repression of CYP1 activity in human skin fibroblasts is not related to AhRR expression. J Invest Dermatol 